\title{
Development, characterization and cytotoxicity evaluation of Gingko biloba extract (EGB761) loaded microemulsion for intra-nasal application
}

\author{
Manisha Singh ${ }^{1}$, Surya Pratap Singh ${ }^{2}$, R. Rachana ${ }^{1 *}$ \\ ${ }^{1}$ Department of Biotechnology, Jaypee Institute of Information Technology,A-10, sector 62, Noida, Uttar Pradesh, India-201307. \\ ${ }^{2}$ Department of Biochemistry, Faculty of Science, Banaras Hindu University, Varanasi-221005, India.
}

\author{
ARTICLE INFO \\ Article history: \\ Received on: 20/07/2016 \\ Revised on: $10 / 08 / 2016$ \\ Accepted on: 02/09/2016 \\ Available online: $31 / 01 / 2017$ \\ Key words: \\ Phytochemicals; \\ Bioavailability; \\ Thermodynamic stability; \\ Particle size analysis; \\ Transmission electron \\ microscopy (TEM); Central \\ nervous system.
}

\begin{abstract}
Background: Ginkgo biloba is therapeutically important fossil species with extended benefits against CNS disorders as; it contains various potential constituents which are known for their specific actions. In spite of this fact its medicinal usage are limited due to the limited absorption, rapid elimination, vigorous biotransformation and low bioavailability of its therapeutic components. Objective: The present study is an attempt to develop a microemulsion system of standardized extract of Ginkgo biloba (EGB761) for intranasal application. Material and methods: It is developed by water titration method using Isopropyl Myristate (oil), Tween 80 (surfactant) and Ethanol (co surfactant). Results: EGB761 loaded microemulsions were developed and characterized. The optimized formulation showed particle size of $259.8 \pm 6.3 \mathrm{~nm}$, PDI score of $0.186 \pm 0.092$ and zeta potential as $9.87 \pm 2.23 \mathrm{mv}$. Also, TEM images showed size range from $84-260 \mathrm{~nm}$ with smooth and spherical morphology. In vitro phyto-constituents release through isolated nasal mucosa showed release pattern of zero order kinetics with sustained release (up to 16 hours). Moreover, cytotoxicity evaluation (RPMI2650 cell lines) didn't show cytotoxicity for both GBME $(99.3 \% \pm 2.28 \%$ and $98.17 \% \pm 1.86 \%)$ and plain EGB761 extract $(95.3 \% \pm 2.1$ and $91.7 \% \pm 1.07)$ with different time periods ( 3 and 12 hours). Conclusion: Therefore, it has been concluded from the results that, EGB761 based microemulsion (GBME) is developed with particle size range between $84-260 \mathrm{~nm}$, having zero order release kinetics. GBME is found to be safe on RPMI2650 cell line and can be further, investigated in in vivo system.
\end{abstract}

\section{INTRODUCTION}

Neurodegenerative disorders (NDD) contribute to around $6.3 \%$ of the global burden of diseases which tends to increase in the coming years due to changing lifestyle and enhanced life expectancy (Murray, 1994 and 1996).

The global economic impact of such disorders alone was more than $\$ 600$ billion in 2010. Therefore, significant research efforts have been directed towards discovering and developing new, improved and cost effective therapies for central nervous system (CNS) disorders (Pankevich, 2014). Despite these efforts, there exist limited efficient treatments for

* Corresponding Author

E-mail: rachana.dr@iitbombay.org neurodegenerative disorders as, one of the biggest barrier for the success of the old as well as new CNS drugs is their inability to profusely cross the blood-brain barrier (BBB) (Nieoullon, 2011). To overcome these limitations, targeted drug delivery vehicles for CNS therapeutics are being extensively explored.

In Alzheimer's disease (AD) there is a phenomenal aggregation of $\beta$-amyloid, tau proteins and other markers of neuronal degeneration in the brain and cerebrospinal fluid, which finally leads to the progression of the dementing process, making it more complex and multifactorial kind of neurodegenerative disease (Ballard et al., 2011). There is no absolute cure for AD and the commercially available FDA approved drugs are mostly cholinesterase inhibitors with uncertain side effects on individuals (Birks, 2006 and McGleenon et al., 1999). 
Several new treatment strategies which are based on medicinal plants have been the subject of current focus due to their less or no side-effects (Rao, 2012). Ginkgo biloba (Family: Ginkgoacea) is one such therapeutically important plant which is well documented for its effects on improvement of memory, increased blood circulation, inhibitor of platelet-activating factor and also as a neuroprotective agent (DeFeudis and Drieu, 2000). Standardized extract of Ginkgo biloba leaves (EGB761) contains $24 \%$ flavonoid glycosides (like - Quercetin, Kaempferol and Isorhamnetine), $6 \%$ terpenoids (ginkgolides $\mathrm{A}, \mathrm{B}, \mathrm{C}, \mathrm{J}-3.1 \%$ and bilobalide - 2.9\%), and 5-10\% organic acids. The flavonoid constituents of this plant (Quercetin, Kaempferol and Isorhamnetine) are especially considered to be the most pharmacological active components responsible for treating various CNS disorders (Chun et al., 2010) but these components either get methylated or degraded very easily in gut or liver (Thilakarathna, 2013) if, taken by conventional oral route. Presently, Ginkgo is sold as an oral medicinal supplement around the world, majorly in United States and European countries for the aforesaid uses. It is one of the topmost selling herbal products in United States since, 1998 (Bent, 2008). Its daily recommended oral dose as per the WHO monograph (1999) and European scientific cooperative on phytotherapy (ESCOP, 2003) is $120-240$ $\mathrm{mg} /$ day. Ginkgo leaf extract have been seen as a potential phytotherapeutic agent in treatment of AD (Oken, 1998). It is reported for its potential anti-oxidant effects and anti-PAF activity also, which inhibits $\beta$-amyloid aggregation in the cerebral cortex, reducing Alzheimer's advancement advancement (Wei et al., 2000). Moreover, the flavonoids (Quercetin and Kaempferol) present in this plant extract, are known to prevent and reduce cell membrane lipid peroxidation, decrease oxidative damage to erythrocytes and protect neurons and retinal tissue from ischemic conditions which in sense might prevent tissue degeneration causing Alzheimer's (Morales, 2014). Medicinal usage of Ginkgo biloba (GB) is limited majorly, due to its low bioavailability (Chan et al., 2007), early degradation, minimal absorption, vigorous biotransformation and rapid elimination (Moreau, 1986; Chen, 2007). Many studies on Gingko leaves extract (GLE) have reported the bioavailability and pharmacokinetic data for plant metabolites of EGB761 showing the metabolites (flavonol glycosides and aglycones) undergo extensive metabolization and degradation (Pietta, 1997; Xie, 2008; Woelkart, 2010). Similarly, brain distribution of some important component of EGB761 like Isorhamnetin and Kaempferol shows that their concentration reaches as low as $161 \mathrm{ng} / \mathrm{g}$ and $291 \mathrm{ng} / \mathrm{g}$ of protein, respectively whereas, for Quercetin it is almost negligible through oral route (Rangel, 2010). Also, when detection of terpene lactones (another important phytochemical of GLE) in both rats and human volunteers was done after oral and intravenous application of EGB761, it was revealed that only traces of GKA (Ginkgolide A), GKB (Ginkgolide B) and BLB (Bilobalide) were present in brain (Biber, 2003). Therefore, all these findings suggest on improving the formulation for more bioavailability, stability and efficiency of the active ingredients. One of the finest approaches which is being actively used, to face these challenges is, nanosized therapeutic compound delivery through intranasal drug delivery (Privalova, Gulyaeva and Bukreeva, 2012). Approaches used for nano-drug delivery are driven by the need to effectively target drugs to the site of disease, to increase patient acceptability and to reduce healthcare costs. This also provides new classes of those pharmaceuticals who cannot be effectively delivered by conventional means. Some of these novel drug delivery approaches includes: lipophilic analogs, prodrug concept, liposomes, polymeric nanoparticles and dendrimers etc. But, these different approaches also have some limitations like - lipophilic analogs and prodrug molecules show low selectivity of drug molecules, change in original tissue distribution of the drug and change efficacy and toxicity levels of used drug (Peters, 2011). Similarly, liposomal formulations need certain surface modifications to enhance their plasma concentration time (Liu, 2014) Although, nanoparticles can effectively permeate through BBB but, their drug transport efficiency to CNS is not enough to give its therapeutic effects, hence functionalization, surface modification along with conjugation is required (Sperling, 2010). Dendrimers based drug delivery systems elicit variation in release kinetic mechanism as, they unload their encapsulated drugs ahead of time to their targets (Wolinsky, 2008). In comparison to the above said problems associated with the new drug dosage forms and novel routes of drug administration, there is a wide acceptance of nano sized drug carrier systems in compliance with microemulsion systems for intranasal application as; there are no reported side effects or any other limitation (Mahajan, 2013) for those. The present study focuses on preparation of microemulsion system for standard extract of Ginkgo biloba (EGB761) for intranasal application. In microemulsion based formulations, the presence of surfactants and co surfactants (act as a permeation enhancers), effectively raises the membrane permeability of test compounds and hence, increase higher penetration to the deeper layer of cortical area (Sahoo, 2007). Moreover, its enhanced spreading effect due to low surface tension and prolonged drug release are other important factors that make it an ideal drug carrier system for intranasal administration (Vandamme, 2002; Lawrence, 2000).

\section{MATERIALS}

The standardized extract of Ginkgo biloba (EGB761) was obtained from the Ranbaxy Research Laboratory, India. RPMI2650 cell lines were procured from National Centre for Cell Science (NCCS), Pune India; DMEM (Dubelco's Modified Eagle Medium), FBS (Fetal Bovine Serum) and IPM (Isopropyl myristate) were obtained from High Media laboratories, Mumbai, Dialysis membrane (D9777), Tween-80 and Tween-20 and Clove Oil were purchased from Sigma Aldrich, US. Whereas, surfactants like, Plurol Oleique, Labrasol and Labrafac were the gift samples from Gattefosse, France. All other chemicals used were of analytical grades. 


\section{METHODS}

\section{Development of microemulsion \\ Selection and Solubility Studies of excipients}

The solubility of the extract in various oils (Clove, Isopropyl Myristate (IPM), Coconut, Sunflower and Soya bean oil), surfactants (Labrasol, Tween80, Tween 20, Plurol Oleique and Labrafac), and co surfactants (Ethanol, Acetic Acid and Methanol) was determined by dissolving an excess amount of extract $(200 \mathrm{mg})$ in $5 \mathrm{ml}$ of each of the selected oils, surfactants, and co surfactants, separately in test tubes and vortexing them for $15 \mathrm{~min}$. The test tubes were then kept at room temperature on a shaker for 72 hours to attain equilibrium. The equilibrated samples were removed from the shaker and centrifuged at $2800 \mathrm{Xg}$ for 15min. (Mandal, 2011) and analyzed by colorimetric methods for flavonoid and phenolic estimation as described later. The excipients with highest drug solubility were chosen.

\section{Phenolic estimation}

The total phenolic content of the extract was determined by the spectrophotometric method (Blainski, Lopes, de Mello, 2013). The standard for the experiment was prepared using Gallic acid $(10 \mathrm{mg} / \mathrm{ml}$ in methanol). $100 \mu \mathrm{l}$ of the extract sample or standard was mixed with $0.5 \mathrm{ml}$ of $0.2 \mathrm{~N}$ of Folin- Ciocalteu agent followed by $4 \mathrm{ml}$ of $7.5 \%$ of $\mathrm{Na}_{2} \mathrm{CO}_{3}$. The phenolic components in the sample were oxidized by the reagent at an alkaline $\mathrm{pH}$, resulting in a blue-colored molybdenum-tungsten complex. The mixture was then incubated for $10 \mathrm{~min}$. at room temperature and for $1 \mathrm{~min}$ at $65^{\circ} \mathrm{C}$. The absorbance was taken at $765 \mathrm{~nm}$.

\section{Flavonoid estimation}

The total Flavonoid content of Ginkgo biloba (EGB761) extract was estimated by the Aluminium Chloride $\left(\mathrm{AlCl}_{3}\right)$ colorimetric method (Quettier et al., 2000; Patel et al., 2011; Stankovic et al., 2011). The concentrates (0.5ml) of Ginkgo biloba extract $(100-1000 \mu \mathrm{g} / \mathrm{ml})$ were blended with $0.1 \mathrm{ml}$ of $5 \% \mathrm{NaNO}_{2}$ and incubated for $5 \mathrm{~min}$. at $25^{\circ} \mathrm{C}$, this was further mixed with 0.1 $\mathrm{ml}$ of $10 \%$ ethanolic solution of Aluminium Chloride $\left(\mathrm{AlCl}_{3}\right)$ and incubated for another $5 \mathrm{~min}$. Absorbance was taken at $510 \mathrm{~nm}$. The standard graph was prepared using Gallic acid $(100-1000 \mu \mathrm{g} / \mathrm{ml}$ in methanol).

\section{Phase studies}

On the basis of solubility studies; IPM was selected as an oil phase, Tween 80 and Ethanol as surfactant and as co-surfactant, respectively. Distilled water was used as an aqueous phase. Thereafter, the existence zones of microemulsion were determined by constructing Pseudo Ternary Phase Diagrams (XLSTAT-Pro) using water titration method (Zhang and Kohn, 2011)where surfactant and co surfactant $\left(\mathrm{S}_{\text {mix }}\right)$ were taken in different ratios $(1: 0,1: 1,1: 2,1: 3,1: 4,1: 5$ and 1:6 ) along with sixteen different combinations of oil and $S_{\text {mix }}(1: 9,1: 8,1: 7,1: 6,1: 5$ 1:4, 1:3.5, 1:3, 3:7, 1:2, 4:6, 5:5, 6:4, 7:3, 8:2, and 9:1) (Syed, Peh, 2014 and Shafiq, Shakeel 2008), after this, the physical state of microemulsion was marked on a pseudo ternary phase diagrams with one axis representing the aqueous phase, second representing oil, and the third representing a mixture of surfactant and co surfactant at fixed $S_{\text {mix }}$ ratio.

\section{Thermodynamic stability studies}

Prepared microemulsion formulations of Ginkgo biloba extract (EGB761) were tested for physical stability by subjecting them to heating and cooling cycle. The microemulsions were incubated at $4{ }^{\circ} \mathrm{C}$ for 3 days followed by $45^{\circ} \mathrm{C}$ again for 3 days $(6$ times). Thereafter the microemulsions were centrifuged at $2800 \mathrm{Xg}$ for $30 \mathrm{~min}$. Those formulations that were found to be stable were further subjected to freeze-thaw cycles as well. The microemulsions were incubated at $-20{ }^{\circ} \mathrm{C}$ for 3 days followed by $25^{\circ} \mathrm{C}$ for another 3 days ( 6 times). After that, the microemulsions $(2 \mathrm{ml})$ were dispersed in the water phase $(100 \mathrm{ml})$ and were analyzed for their physical stability (Fahima et al., 2011). The formulations which did not show any phase separations, creaming, cracking or coalescence were taken further for the characterization studies (Fanun, 2010).

\section{Characterization}

\section{Measurement of Particle size, Poly dispersity index and Zeta potential}

The average Particle Size (PS), Poly Dispersity Index (PDI) and Zeta potential (ZP) of the optimized microemulsion droplets were determined by Photon Correlation Spectroscopy (1000 HS, Malvern Instrument, UK) at $633 \mathrm{~nm}$ which is based on the principle of dynamic light scattering, which was monitored at $90^{\circ}$ angle $\left(25^{\circ} \mathrm{C}\right)$. The optimized microemulsion samples were diluted (1:50 with mili Q water), and then loaded for droplet size and Zeta potential analysis (Wang et al., 2011).

\section{Statistical Analysis for optimization of microemulsion}

Correlation analysis is used to study the correlation between Particle Size (PS), Oil (O), Surfactant (S) and Water (W); and Poly Dispersity Index (PDI), O, S and W. To establish the relationships between $\mathrm{PS}$ and $\mathrm{O}, \mathrm{S}, \mathrm{W}$; along with $\mathrm{PDI}$ and $\mathrm{O}, \mathrm{S}$, $\mathrm{W}$, regression analysis is done. The data are statistically tested at $1 \%$ level of significance by one way analysis of variance (ANOVA) (Juškait et al., 2015).

\section{Transmission Electron Microscopy (TEM)}

The size and morphology of the samples were further confirmed by Transmission Electron Microscopy (Morgagni 268D Transmission Electron Microscope). Combination of different magnification and diffraction modes were explored to mark the form and size of microemulsion droplets. The sample was prepared by diluting the optimized microemulsions (1: 100 with mili Q water) and placing it in the centre of carbon-coated copper grid with $2 \%$ phosphotungstic acid; the dried coated grid was taken on a slide and covered with a cover slip. The slide was observed under the electron microscope (Monteagudo, 2012). 


\section{Measurement of Rheological parameters (Viscosity, Conductivity, pH and Density)}

Viscosity of the optimized microemulsion was measured with a Brookfield rotational viscometer (LVDV, Brookfield Inc., USA) $\left(30{ }^{\circ} \mathrm{C}\right)$ at $5 \mathrm{rpm}$. Similarly, Conductivity was determined with conductometer (CM 180, Elico, India) at constant frequency of $1 \mathrm{~Hz}$. The $\mathrm{pH}$ was measured by using a calibrated digital $\mathrm{pH}$ meter (Mettler Toledo MP 220, Greifensee, Switzerland) in triplicates at room temperature. Whereas, the density of the formulated microemulsion was measured using specific gravity bottle (Khalil, 2012).

\section{Fourier Transform Infra Red (FT - IR) Analysis}

FTIR analysis for the optimized microemulsion without extract (EGB761), with extract and Gingko biloba standard extract (EGB761) was done using IR-810, JASCO, Tokyo (MacDonald et al., 1986) at SAIF (Sophisticated analytical instrumentation facility), Punjab University. The samples were prepared by potassium bromide disc method and were scanned from 400-4000 $\mathrm{m} / \mathrm{sec}$ (Deepak and VedhaHari, 2013).

\section{In vitro drug diffusion studies using nasal mucosa}

In vitro permeation of optimized Gingko biloba (EGB761) extract microemulsion was carried out on fresh nasal mucosa of sheep which was carefully removed from the nasal cavity of the same, obtained from the local slaughter house and stored in nasal simulated fluid (pH - 6.8) (Schmidt et al., 1998). This membrane was mounted between Franz diffusion cell compartments, held together with a clamp.

The receptor compartment was filled with $10 \mathrm{ml}$ nasal simulated fluid (pH 6.8) (Wadell et al., 2003) and the temperature was maintained at $37{ }^{\circ} \mathrm{C}$. $2 \mathrm{ml}$ of formulated microemulsion or pure extract (aqueous solution, $20 \mathrm{mg} / \mathrm{ml}$ ) was placed in donor chamber one by one and samples $(1 \mathrm{ml})$ were withdrawn from the receptor compartment, replacing with equal volume of nasal simulated fluid after each sampling at predetermined time points (0-8 hrs, at 30 minutes time intervals).

The samples withdrawn were used for LC-MS estimation analysis to determine the amount of extract permeated through membrane at different time points.

\section{Release kinetics: LC-MS method}

LC-MS method was opted to measure the level of majorly active phytoconstituents (Quercetin, Kaempferol and Isorhamnetine) of the extract in diffusion cell experiments. The system (ALS 1290 series; USA) consist of binary pump, vacuum degasser and auto-sampler system connected electro spray ionization (ESI) source). Samples obtained from Franz diffusion cell were injected, using acetonitrile and $0.1 \%$ formic acid in water $(50: 50, \mathrm{v} / \mathrm{v}$ ) pumped at a constant flow of $0.3 \mathrm{ml} / \mathrm{min}$ (Duan et al., 2011; He et al., 2013). The standard graphs for the pure components (Quercetin, Kaempferol and Isorhamnetine) were made within the range of $2.5-15 \mathrm{mg} / \mathrm{ml}$ for each component.

\section{Statistical Methods}

All the data is expressed as mean \pm standard error and tested using one way ANOVA. The values were considered significant at $\mathrm{p}$ values $<0.01$.

Further, to analyze the order of release kinetics, F statistics was used with elution profile (LC-MS estimation) of the marker compounds present in the extract and microemulsions were plotted. To study the significance of differences in the concentrations of the three extract compounds (Quercetin, Kaempferol and Isorhamnetine) one way ANOVA (Analysis of Variance) is applied at $1 \%$ level of significance.

\section{In vitro cytotoxicity studies: MTT assay with nasal epithelial (RPMI2650) cell line}

The cytotoxicity of Gingko biloba (EGB761) extract microemulsion was tested on the human nasal septum cell line (RPMI2650) (Moorhead, 1965) using MTT assay (Nag et al., 2015). The said cell line was maintained in DMEM (Dulbecco's Modified Eagle's medium) media (10\% FBS), in standard conditions. The cells were trypsinised and seeded at the concentration of $5.0 \times 10^{5}$ cells $/ \mathrm{ml}$ in triplicates. The cells were incubated at $5 \% \mathrm{CO}_{2}$ and $37{ }^{\circ} \mathrm{C}$ overnight to allow the cells to adhere. Thereafter, the cells were treated with different concentrations $(10-100 \mu \mathrm{g} / \mathrm{ml})$ of standard extract of Gingko biloba (EGB761) and its microemulsion (GBME) separately, for 3 and 24 hours. Subsequent to the incubation, $20 \mu 1$ of MTT solution $(5 \mathrm{mg} / \mathrm{ml})$ were added to the respective wells and incubated again for 4 hours. Formazan crystals formed during this period were dissolved in $200 \mu \mathrm{l}$ of DMSO and the optical density was determined at $570 \mathrm{~nm}$ (Loosdrecht et al., 1994).

\section{RESULT AND DISCUSSION}

\section{Selection of excipients}

The excipients were selected keeping in mind the pharmaceutically accepted GRAS (generally regarded as safe) limits and non irritating nature of the substances (to nasal mucosa). Selection of surfactant and co surfactant was done on the basis of hydrophile-lipophile balance (HLB) value which should be between $8-18$ in case of o/w microemulsions (Davies and Rideal, 1968) moreover non-ionic surfactants were preferred over ionic ones as they are less toxic (Sahoo et al., 2014) and Co surfactants are added as they decrease the bending stress of interface leading to the formation of more flexible interfacial film over a wide range of composition. The required hydrophilic-lipophilic balance value to form the o/w microemulsion should be greater than 10 (Patel et al., 2013). Therefore, the right blend of low and high hydrophiliclipophilic balance surfactants leads to the formation of a stable microemulsion formulation.

Phenols and Flavonoid content found to be in extract was $67.41 \pm 0.23 \mathrm{mg} / \mathrm{ml}$ and $46.13 \pm 1.28 \mathrm{mg} / \mathrm{ml}$, respectively and Table 1 shows the results of solubility of extracts in terms of Flavonoid and Phenol content in various excipients. On the basis of these results, Isopropyl Mystriate (IPM), Tween 80 (HLB value 
is 15) and Ethanol (HLB value is 4.2) were selected for oil, surfactant and co surfactant phase, respectively. Here distilled water was used as an aqueous phase.

Table 1: Solubility analysis of various oils, surfactant and co surfactant with Gingko biloba (EGB761) extract.

\begin{tabular}{lcc}
\hline Excipients & $\begin{array}{c}\text { Solubility }(\mathbf{m g} / \mathbf{m l}) \text { of } \\
\text { Phenols }\end{array}$ & $\begin{array}{c}\text { Solubility }(\mathbf{m g} / \mathbf{m l}) \text { of } \\
\text { Flavonoids }\end{array}$ \\
\hline Oils & & \\
\hline Isopropyl Myristate & $70.12 \pm 2.09$ & $41.34 \pm 1.70$ \\
Capryol 90 & $47.1 \pm 0.03$ & $35.76 \pm 1.62$ \\
Olive oil & $59.63 \pm 0.05$ & $37.13 \pm 2.96$ \\
Castor oil & $63.87 \pm 1.48$ & $25.33 \pm 0.85$ \\
Linseed oil & $35.62 \pm 0.07$ & $14.72 \pm 1.1$ \\
\hline Surfactants & \\
\hline Tween-80 & $62.02 \pm 1.5$ & $36.4 \pm 0.8$ \\
Tween 20 & $48.5 \pm 1.09$ & $20.27 \pm 0.27$ \\
Cremophor RH40 & $33.92 \pm 2.2$ & $13.92 \pm 1.2$ \\
Transcutol P & $26.2 \pm 1.64$ & $18.6 \pm 1.03$ \\
Plurol oleique & $15.39 \pm 0.12$ & $23.92 \pm 0.85$ \\
\hline Co - Surfactant & \multicolumn{3}{|}{} \\
\hline Ethanol & $65.34 \pm 3.87$ & $44.2 \pm 2.62$ \\
Propranolol & $12.8 \pm 1.56$ & $32.6 \pm 2.7$ \\
\hline
\end{tabular}

\section{Phase studies}

The pseudo ternary phase diagram plotted shows the relationship between the phase behaviour of a mixture and its composition and was constructed to reveal the existence range of microemulsion. Pseudo ternary Phase Diagrams (Fig.1 (a) and Fig.1 (b)) were constructed, separately for each $\mathrm{S}_{\text {mix }}$ ratio (1:0 and $1: 1$ ) for getting $\mathrm{o} / \mathrm{w}$ microemulsion regions.

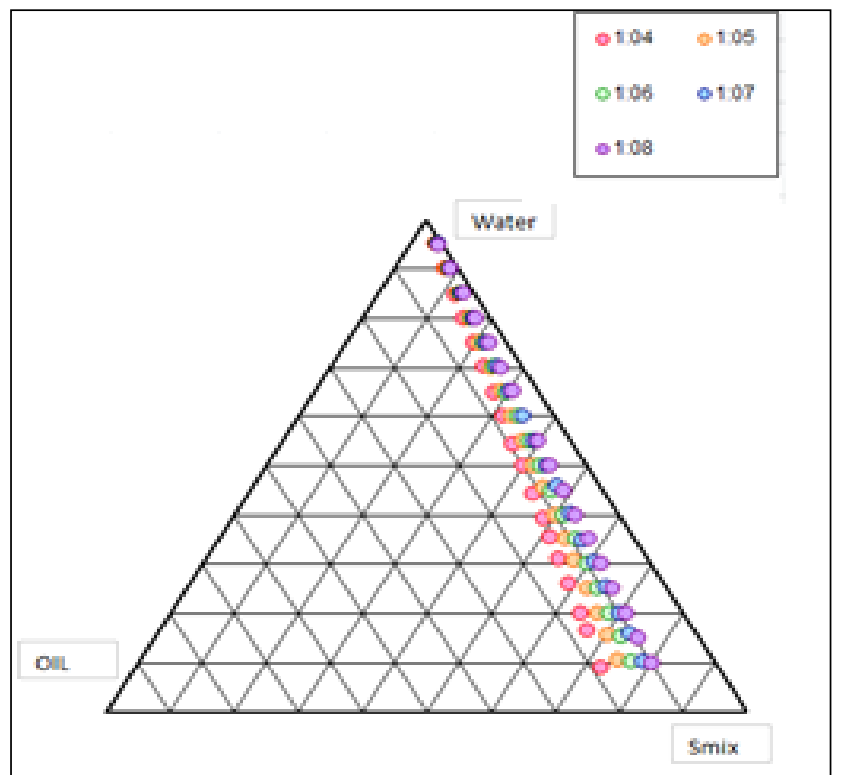

Fig. 1(a): Pseudoternary phase diagram indicating o/w microemulsion using isopropyl myristate (Oil), tween 80 (Surfactant) and ethanol (Co surfactant) with $\mathrm{S}_{\text {mix }}$ ratio of 1:0.

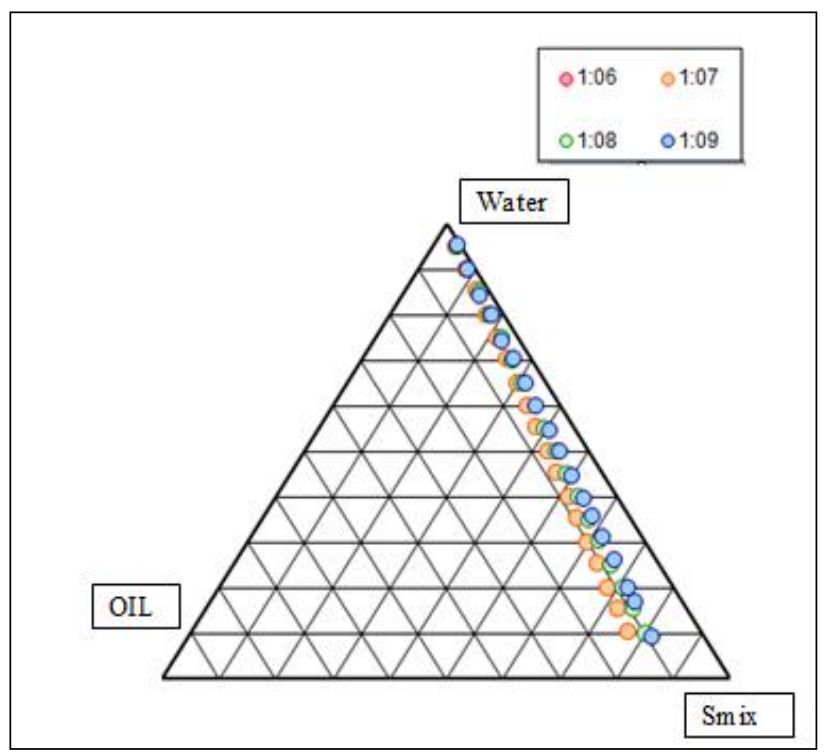

Fig. 1(b): Pseudoternary phase diagram indicating $\mathrm{o} / \mathrm{w}$ microemulsion using isopropyl myristate (Oil), tween 80 (Surfactant) and ethanol (Co surfactant) with $\mathrm{S}_{\text {mix }}$ ratio of 1:1.

As, the ratio of surfactant was increased, the isotropic region showed a shift towards $S_{\text {mix. }}$. The ternary phase study revealed that on increasing the $S_{\text {mix }}$ ratio from 1:0 to $1: 1$, microemulsion region decreases towards oil axis and the increase in $\mathrm{S}_{\text {mix }}$ content may dispense a suitable option to the flavonoid (Quercetin, Kaempferol, Isorhamnetine) and phenolic content of the extract to solubilize more to the surfactant (Tween 80) and co surfactant (Ethanol). From the earlier reported studies also, it was observed that the solubility and bioaccessibility of Quercetin have significantly increased in Tween 80 (Sahoo et al., 2011; Pool et al., 2013) whereas, Kaempferol and Isorhamnetine have been reported to be more soluble in ethanol (Kumar and Pandey, 2013). Moreover, the micelle formation in microemulsion also, increases their stability for longer duration (Lof, 2011). The area of solubilization in the phase diagrams indicates the clear and homogenous solutions.

\section{Characterization of microemulsions \\ Particle size (PS), polydispersity index (PDI) and Zeta potential $(\mathrm{ZP})$}

After testing the thermodynamic stability among all the emulsions developed, three formulations (IT - A to IT - C) were listed and found to be from 221 to $259 \mathrm{~nm}$ range (Table 2), using zeta particle size analyzer indicating droplets size from nano to micro range. On the basis of polydispersity index IT - A was selected with an average particle size of $259.8 \mathrm{~nm}$ and PDI of 0.186 (Table 2 and Figure 2 (a).

Table 2: Summarization of ratio and content of excipients, Particle size and Polydispersity Index of the optimized microemulsions.

\begin{tabular}{|c|c|c|c|c|c|c|c|c|}
\hline S. No & Ratio & Ratio $_{S_{\text {mix }}}$ Oil : & Code & $\begin{array}{c}\text { Oil } \\
(\%)\end{array}$ & $\mathrm{S}_{\text {mix }}(\%)$ & Water (\%) & $\begin{array}{l}\text { Particle Size } \\
\text { (d.nm) }\end{array}$ & $\begin{array}{c}\text { Poly } \\
\text { dispersity Index (PDI) }\end{array}$ \\
\hline 1 & \multirow{3}{*}{ 1:01 } & & IT $-\mathrm{A}$ & 6.45 & 58.06 & 35.48 & 259.8 & 0.186 \\
\hline 2 & & 1:09 & IT $-B$ & 6.06 & 54.55 & 39.39 & 250.4 & 0.436 \\
\hline 3 & & & IT $-\mathrm{C}$ & 5.56 & 50 & 44.44 & 221 & 0.605 \\
\hline
\end{tabular}




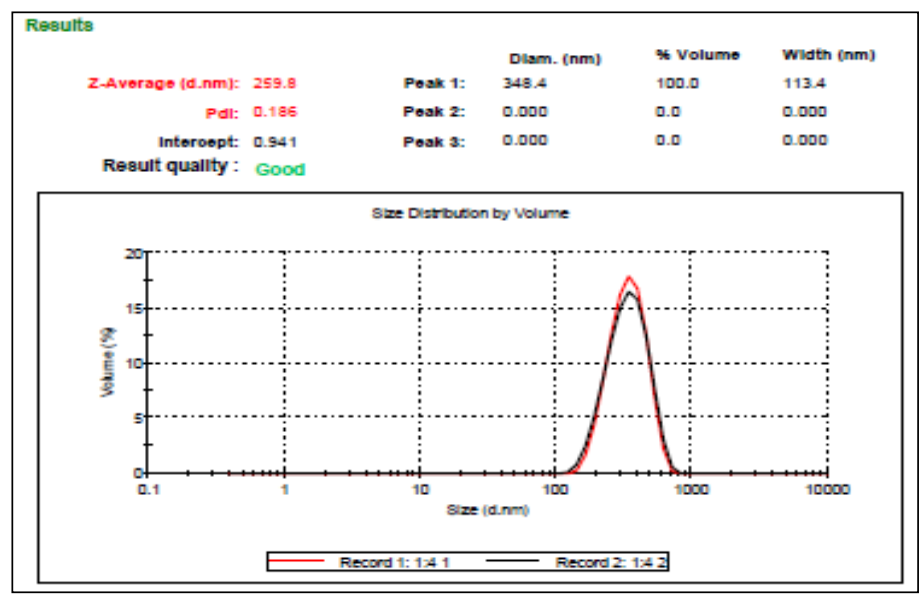

Fig. 2 (a): Particle size analysis of the optimized microemulsions (IT - A).

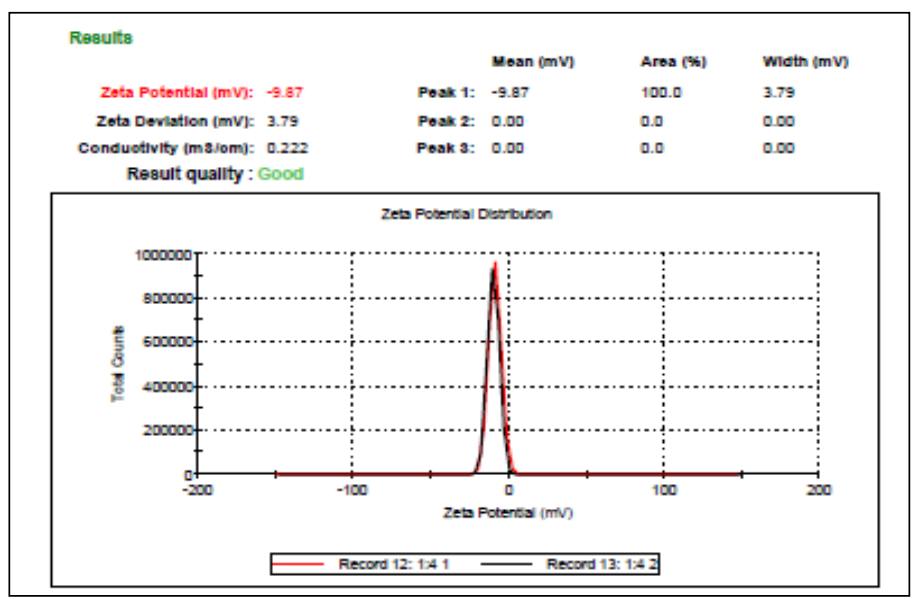

Fig. 2 (b): Zeta Potential of the optimized microemulsions (IT - A).

The Polydispersity Index shows the width of particle size distribution, indicating nature of dispersion, which ranges between 0 to 1 . PDI Values $\leq 0.5$ are considered as highest quality of dispersion and show narrow size distribution (Atkins, 2010). The available experimental data with the same combination of excipients showed comparatively lower size range as, in case of Acyclovir microemulsion systems where, size range is $40.2 \pm 2.3$ $\mathrm{nm}$ (Dedakia and Majumdar, 2012) and in case of Diclofenac microemulsion was between 5-7 nm (Kamal et al., 2007). Whereas, in the present study it reflects comparatively bigger spherical size (221 to $259 \mathrm{~nm}$ ) which can be due to the fact that Gingko biloba (EGB761) extract is a complex mixture and not a pure compound. The optimized Gingko biloba (EGB761) extract microemulsion (IT-A) has a PDI value of 0.186 , suggesting a homogenous distribution of microemulsions.

Zeta potential of the formulation reflects its polarity and electric potential constituted by availability of charge (positive or negative) on the surface of particle (Clogston and Patri, 2011). The zeta potential of optimized formulation (IT - A) was recorded as (-) $9.87 \mathrm{mV}$ (Figure 2 (b)) indicating the fact that non ionic surfactants (Tween 80) decrease the zeta potential charges on the surface of micelles formed (Sis and Birinci, 2012) and hence, leads to the prevalence of repulsive forces thereby, avoiding flocculation and aggregation of the formulated micelles present in a continuous phase.

\section{Transmission Electron Microscopy (TEM)}

TEM has been used by various scientists to analyze and validate the particle size and morphology (Patel et al., 2013). Figure 3 represents the TEM micrographs of the particles of optimized formulation (IT - A).

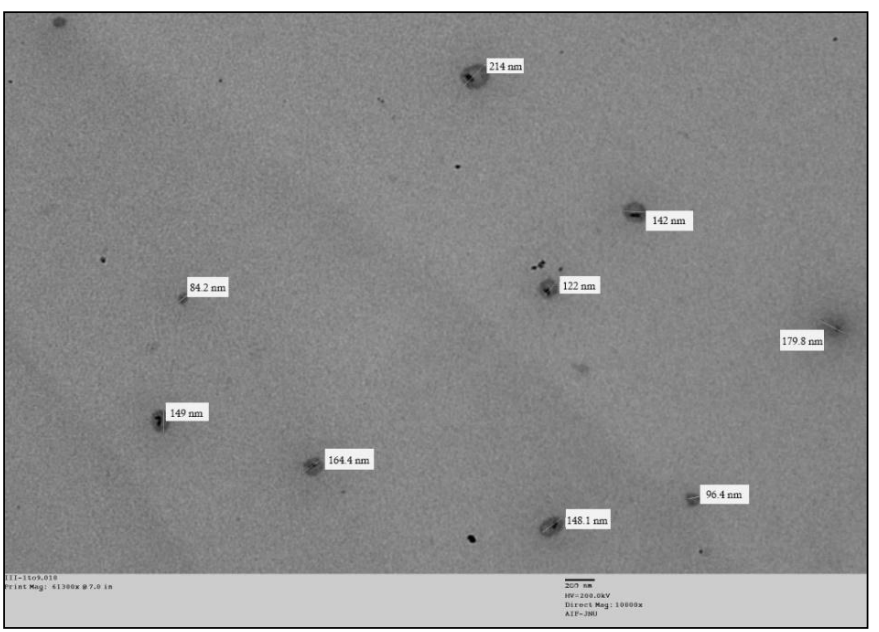

Fig. 3: TEM image of the optimized drug loaded microemulsion at $10,000 x$ (scale bar showing $200 \mathrm{~nm}$ ).

The particles observed were finely distribute and in spherical nanometric size range $(84 \mathrm{~nm}$ to $260 \mathrm{~nm})$. Hence, the globule sizes of GBME from TEM images are in conformity with particle size analysis $(259.8 \mathrm{~nm})$ performed earlier with zeta particle size analyzer.

\section{Measurement of Rheological parameters (Viscosity, Conductivity, $\mathrm{pH}$ and Density)}

Molecular volume and effective carbon number of oil are important factors that determine the viscosities of microemulsions. In the present study, IPM is selected for oil phase, which has a saturated long chain with 14 effective carbon numbers, making it more flowable (Paul and Moulik, 2000). Also, presence of tween 80 which is a denser surfactant $(300 \mathrm{cP})$ alone could have affected the viscosity. In the present study tween 80 is used in combination with ethanol as Co surfactant, as alcohols are believed to join the interface of the micelle, by placing itself among surfactant heads. This increases the dielectric constant and the degree of ionization (Prieto and Calvo, 2013). Moreover, its presence also leads to the distortion of water structure by improving the lipophilic nature of tween, allowing it to be more available for interphase. So, the viscosity of the microemulsion (IT - A) formulation was measured as, $38 \pm 1.01 \mathrm{cP}$ which is desired to be in the range of $30-45 \mathrm{cP}$ in case of o/w microemulsions (Sarkhejiya, 2013).

The specific conductivity of microemulsion was found to be $22 \mathrm{mS} / \mathrm{m}$ which is of the same order of aqueous conductivity. Since external phase is aqueous with $\mathrm{pH} 6.7$, it is suitable for intranasal application in the nasal cavity ( $\mathrm{pH} 6.4$ - 6.8) (Washington et al., 2000) (Table 3). 


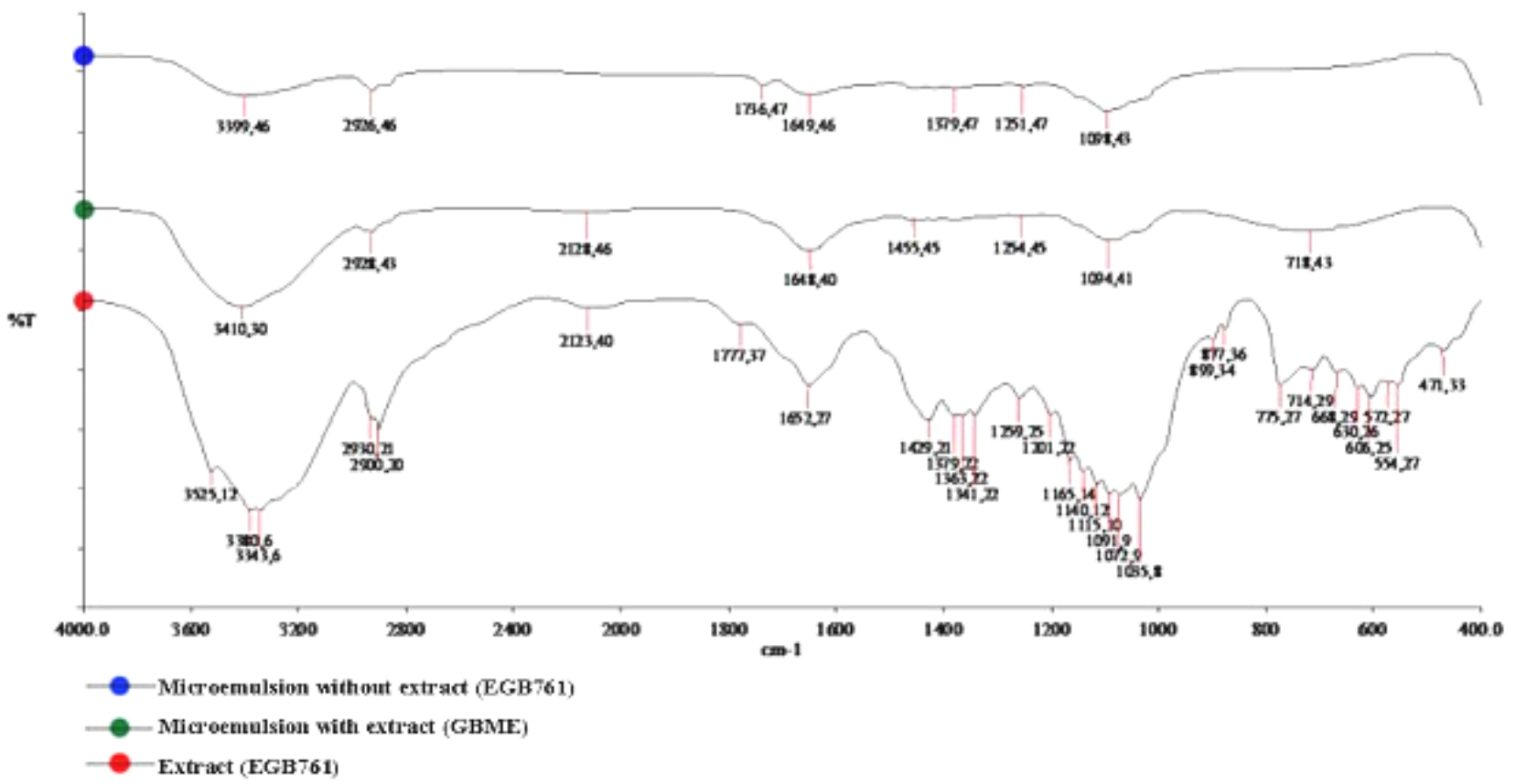

Fig. 4: FT-IR analysis of the plain Gingko biloba extract (EGB761), optimized extract loaded microemulsion (GBME) and microemulsion without extract.

Table3: Summarization of rheological parameters of the optimized microemulsions.

\begin{tabular}{ccc}
\hline S.No & Parameters & Result \\
\hline 1 & Viscosity & $38 \pm \mathrm{cP}$ \\
2 & Conductivity & $22 \pm \mathrm{mS} / \mathrm{m}$ \\
3 & $\mathrm{pH}$ & $6.7 \pm 0.01$ \\
4 & Density & $1.16 \pm \mathrm{g} / \mathrm{mL}$ \\
\hline
\end{tabular}

\section{FT-IR Analysis}

In order to investigate the potential interaction, if any, among various ingredients of the microemulsion, FTIR spectroscopy was performed for EGB761 extract powder, optimized microemulsion concentration without extract and, optimized microemulsion with extract (GBME). A small amount of the samples were directly scanned for absorbance over a range from 4,000 to 400 wave numbers (cm-1) (Heneczkowski, 2001 and HaiyanXie et al., 2014). The significant peaks of flavone group (1028 - $1649 \mathrm{~cm}-1)$ were observed in scan of the extract (Figure 4) which, were shifted in the scan of GBME and, the scan of GBME was also in accordance to the one of microemulsion without extract. Therefore, it can be concluded from the observations that the characteristics peaks of GBME almost followed the same path as that of EGB761, reflecting no interaction between the components of the extract and the ingredients of microemulsion.

\section{Permeability release kinetics}

The three active constituents (Quercetin, Kaempferol and Isorhamnetine) of EGB761 were estimated in the samples obtained from receptor compartment of the Franz diffusion cell, after every $30 \mathrm{~min}$ (from 0 to $16 \mathrm{hrs}$ ) and were estimated by LC MS method (Figure 5). The values obtained were plotted.

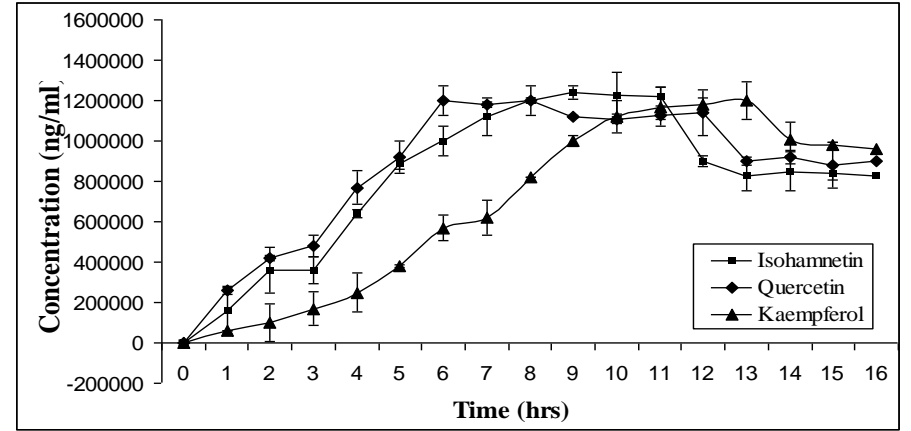

Fig. 5: Release pattern of three active constituents (Isorhamnetine, Quercetin, and Kaempferol) of EGB761 through nasal mucosa.

The release patterns of all the three active compounds (Quercetin, Kaempferol and Isorhamnetine) in standardized extract of Ginkgo biloba (EGB761) were showing close to zero order kinetics up to 10 hours after which there was a drop in release.

The values obtained for the three active compounds (Quercetin, Kaempferol and Isorhamnetine) for GBME were also plotted and analyzed for the release pattern of various order, using F Statistics (Figure 6-8). It was found that the equations derived for GBME were of zero order kinetics for all the three components. Further, the release behaviour was showing a sustained release pattern up to $16 \mathrm{hrs}$, in comparison to plain extract. Table 1 summarizes the determination coefficients $\left(R^{2}\right), F$ values and $\mathrm{p}$-values for the models of all the three compounds. It can be noticed that $\mathrm{R}^{2}$ values for all the three drugs are very high $(>0.90)$ and the respective $\mathrm{p}$-values for all the three compounds are significant (at $\mathrm{p}<0.01$ ). This indicates that the calculated zeroorder models fit the release kinetics of all the three compounds (Isorhamnetine, Quercetin, and Kaempferol) (Dash et al., 2010) 


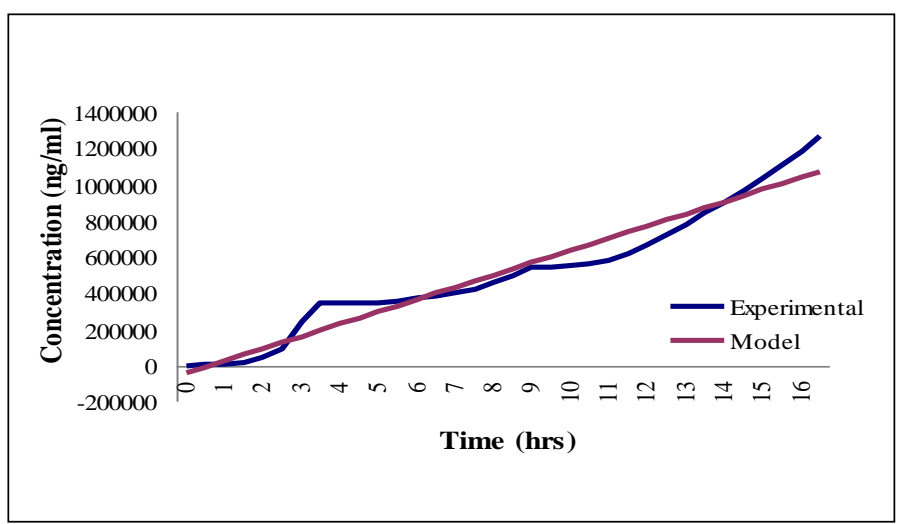

Fig. 6: In vitro compound release pattern analysis of Isorhamnetine from GBME.

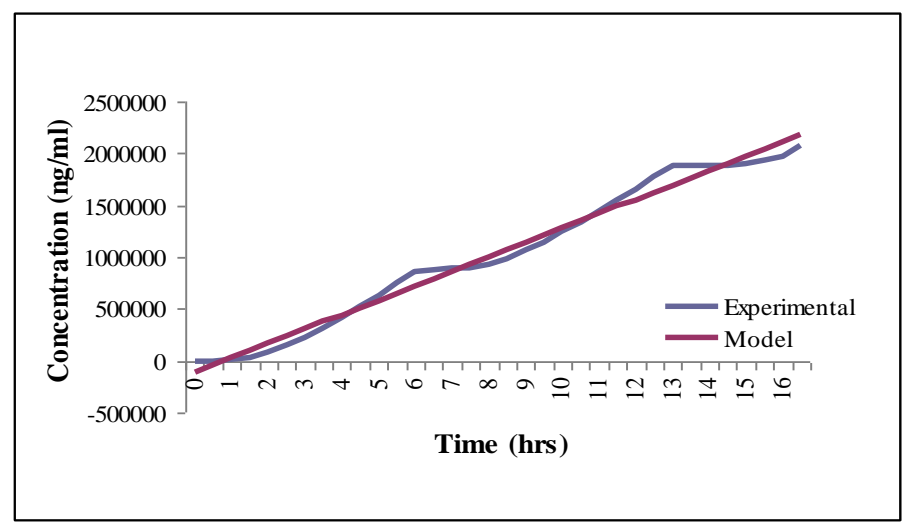

Fig. 7: In vitro compound release pattern analysis of Quercetin from GBME.

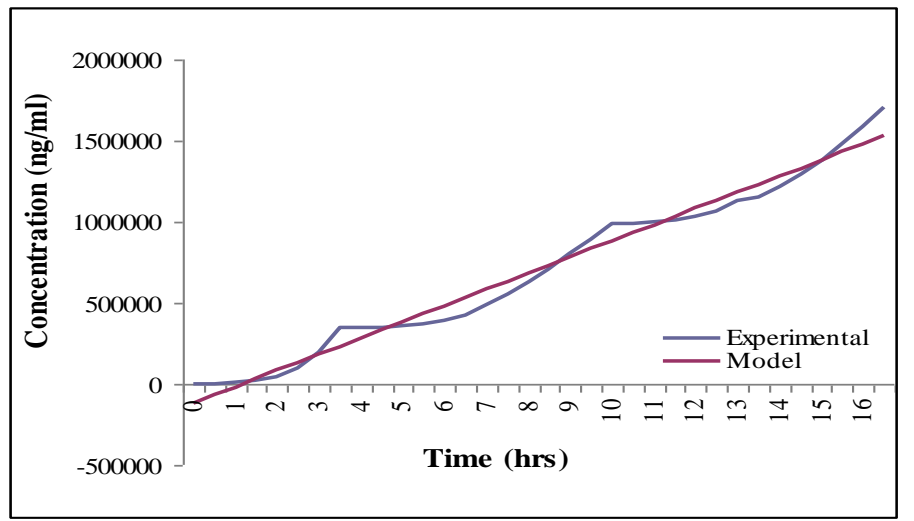

Fig. 8: In vitro compound release pattern analysis of Kaempferol from GBME.

\begin{tabular}{cccc}
\hline & Isorhamnetine & Quercetin & Kaempferol \\
\hline $\mathbf{R}^{2}$ & 0.947071 & 0.984688 & 0.979987 \\
$\mathbf{F}$ & 572.582 & 2057.899 & 1566.993 \\
$\mathbf{p ~ v a l u e}$ & $5.45 \mathrm{E}-22$ & $1.29 \mathrm{E}-30$ & $9.35 \mathrm{E}-29$ \\
\hline
\end{tabular}

The general equation for the zero-order kinetic model is given by equation (1).

$$
\mathrm{Q}_{\mathrm{t}}=\mathrm{Q}_{0}+\mathrm{K}_{0 \mathrm{t}}
$$

Where $Q_{t}$ is the amount of drug released in time $t$ and $Q_{0}$ is the initial amount of drug. The linear equations (2) - (4) describe the release kinetics of all the three above mentioned compounds, where Q1 (t), Q2 (t) and Q3 (t) represent the estimated amount of concentration in time $\mathrm{t}$ for Isorhamnetine, Quercetin, and Kaempferol, respectively (Ramteke et al., 2014).

$$
\begin{aligned}
& \text { Q1 }(\mathrm{t})=-41972.75+33851.79 \mathrm{t} \ldots(2) \\
& \text { Q2 }(\mathrm{t})=-111489.90+69443.82 \mathrm{t} \ldots \text { (3) } \\
& \text { Q3 }(\mathrm{t})=-116561.60+49928.85 \mathrm{t} \ldots \text { (4) }
\end{aligned}
$$

The numerical results for cumulative amount of compound release, obtained through zero-order kinetic models, using equations (1) (4) are compared with the experimental results, are illustrated in figures $6-8$

\section{In vitro cytotoxicity studies: RPMI 2650 cell lines}

To evaluate and compare the cytotoxicity caused by GBME in comparison to plane EGB761, MTT assay was performed at different concentrations $(10-100 \mu \mathrm{g} / \mathrm{ml})$ of extract, on RPMI 2650 cell line (nasal epithelial). It was observed that the test concentration range $(10-100 \mu \mathrm{g} / \mathrm{ml})$ of Gingko biloba extract (EGB761) microemulsion was not significantly toxic (cell viability $99.3 \% \pm 4.28 \%$ and $98.67 \% \pm 5.86 \%$, respectively) after 3 hours and 12 hours of exposure.

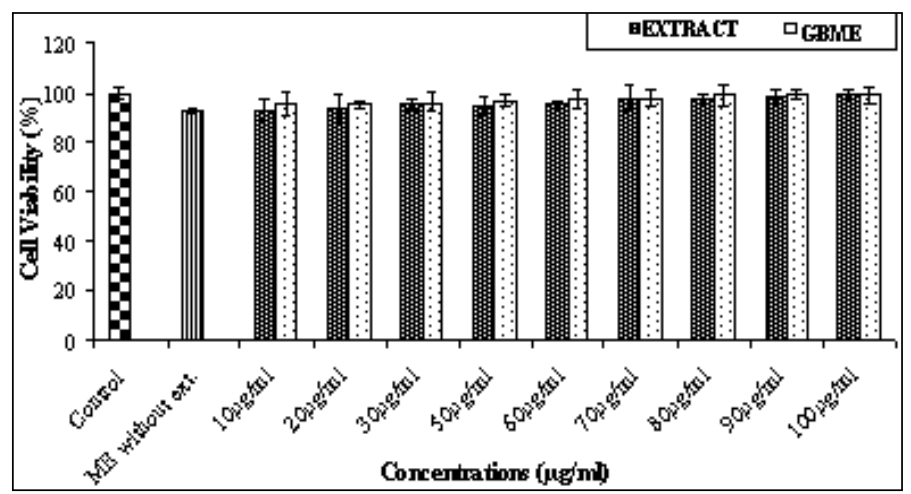

Fig. 9: Cytotoxcity analysis of the optimized extract microemulsion, with and without extract, after 3 hours of treatment. Abbreviations: ME without ext. = Microemulsions without EGB761 extract, GBME = Microemulsions of standard extract of Ginkgo biloba EGB761.

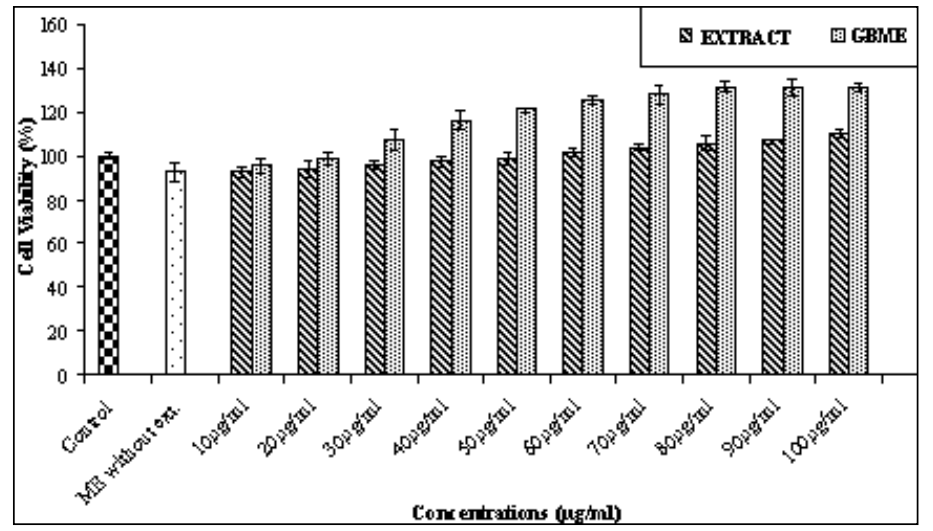

Fig. 10: Cytotoxicity analysis of the optimized extract, microemulsion with and without extract, after 3 hours of treatment after 12 hours of treatment. Abbreviations: ME without ext. = Microemulsions without EGB761 extract, GBME $=$ Microemulsions of standard extract of Ginkgo biloba EGB761. 


\section{CONCLUSION}

Ginkgo biloba is therapeutically important plant for CNS disorders as; it contains various potential constituents like: Isorhamnetine, Quercetin, and Kaempferol etc. Unfortunately, its medicinal usages are limited due to the limited absorption, rapid elimination, vigorous biotransformation and low bioavailability of its therapeutic components. The present study was an attempt to overcome the above said issues by developing a formulation in nano range. After optimizing all the experimental conditions, the microemulsion of the extract was prepared using Isopropyl mystriate as oil phase, Tween 80 as surfactant, ethanol as cosurfactant and distilled water as aqueous phase. The average particle size of the micro spheres was observed to be in nanometric range $(84 \mathrm{~nm}$ to $260 \mathrm{~nm}$ ). The said microemulsion was thermodynamically stable and exhibited approximately $56-77 \%$ of compound (Quercetin, Kaempferol and Isorhamnetine) release with sustained pattern (up to $16 \mathrm{hrs}$ ) from the isolated nasal mucosa. The release kinetics of its active phytoconstituents was found to be of zero order. Cytotoxicity analysis of the formulation showed that microemulsion did not have deteriorating effect on cell viability in the concentration range of $10-100 \mu \mathrm{g} / \mathrm{ml}$ up to 12 hrs. Thus, it can be suggested from the present study that as the developed microemulsion is showing sustains release with zero order kinetics and $\sim 77 \%$ release of its content, GBME could further be developed and tested in in vivo for intranasal delivery as an alternative delivery system for the treatment of CNS disorders.

\section{Financial support and sponsorship: Nil.}

Conflict of Interests: There are no conflicts of interest.

\section{REFERENCES}

Ballard C, Gauthier S, Corbett A, Brayne C, Aarsland D, Jones E. Alzheimer's disease. Lancet, 2011; 377(9770):1019-31.

Birks J, Cholinesterase inhibitors for Alzheimer's disease. Cochrane Database Syst, 2006; (1):CD005593.

Bent S. Herbal Medicine in the United States: Review of Efficacy, Safety, and Regulation. J Gen Intern Med, 2008; 23(6): 854-859.

Blainski A, Lopes GC, Palazzo de Mell JC.Application and Analysis of the Folin Ciocalteu Method for the Determination of the Total Phenolic Content from Limonium Brasiliense L. Molecules, 2013; 18: 6852-6865.

Biber A. Pharmacokinetics of Ginkgo biloba extracts. Pharmacopsychiatry, 2003; 36:S32-S37.

Chun S, Jun L, Fengming W, David TY.Ginkgo biloba Extract in Alzheimer's Disease: from Action Mechanisms to Medical Practice.Int J Mol Sci., 2010; 11(1): 107-123.

Chan PC, Xia Q, Fu PP. Ginkgo biloba leave extract: Biological, medicinal and toxicological effects. J. Environ. Sci. Health C. Environ. Carcinog.Ecotoxicol. Rev., 2007; 25: 211-244.

Chen WD, Liang Y, Xie L, Lu T, Liu XD, Wang GJ. Pharmacokinetics of the ginkgo B following intravenous administration of ginkgo B emulsion in rats. Biol Pharm Bull., 2007; 30(1): 1-5.

Clogston JD, Patri AK.Zeta potential measurement. Methods Mol Biol., 2011; 697: 63-70.

De Feudis FV, Drieu K. Ginkgo biloba extract (EGB761) and CNS functions: basic studies and clinical applications. Curr Drug Targets, 2000; 1(1):25-58.

Duan K, Yuan Z, Guo W, Meng Y, Cui Y, Kong D, Zhang L, Wang N. LC-MS/MS determination and pharmacokinetic study of five flavone components after solvent extraction/acid hydrolysis in rat plasma after oral administration of Verbena officinalis L. extract. J Ethnopharmacol, 2011; 17; 135(2):201-8.

Deepak SN, VedhaHari BN. Optimization, Development and evaluation of Microemulsion for the release of combination of Guaifenesin and Phenylephrine, J App. Pharm. Sci., 2013; 3 (9): 48-56.

Davies JT, Rideal EK. 1963. Interfacial Phenomena, 2nd ed. London, UK: Academic Press.

Dedakia J, Majumdar SH. Formulation And Evaluation Of Microemulsion Based Tablets Of Acyclovir For Better Patient Compliance, Int. J. Pharm Tech. Res., 2012; 4 (4):1730-1734.

Dash S, Murthy PN, Nath L, Chowdhary P. Kinetic modeling on drug release from controlled drug delivery systems, Acta Poloniae Pharmaceutica - Drug Res., 2010; 67( 3):217 - 223.

Enam K, ShorouqTAl-S, Mutasem OT. Formulation and Characterization ofIPM/Water/Nonionic-Ionic Surfactant Microemulsions, J. Chem. Eng., 2012; 6187-6198.

European Scientific Cooperative on Phytotherapy, "E/S/C/O/P monographs: the scientific foundation for herbal medicinal products", 2. ed. Exeter (Great Britain) : ESCOP ; Stuttgart : Thieme. pp 65-68.

Fahima MH, Dalia SS, Mohamed KG, Mohamed N, Aliaa I. Formulation, Characterization, and Clinical Evaluation of Microemulsion Containing Clotrimazole for Topical Delivery. AAPS Pharm SciTech, 2011; 12(3): 879-886.

Fanun M. Microemulsions with nonionic surfactants and mint oil, Coll. Sci. J., 2010; 3:9-14.

He J, Feng Y, Ouyang HZ, Yu B, Chang YX, Pan GX, Dong GY, Wang T, Gao XM. A sensitive LC-MS/MS method for simultaneous determination of six flavonoids in rat plasma: application to a pharmacokinetic study of total flavonoids from mulberry leaves. J Pharm Biomed Anal., 2013; 84:189-195.

Hadjiioannou TP, Christian GD, Koupparis MA, Macheras PE. 1993. Quantitative Calculations in Pharmaceutical Practice and Research, 1sted. New York, USA: VCH Publishers.

Heneczkowski M, Kopacz M, Nowak D, Kuzniar. Infrared spectrum analysis of some flavonoids, Actapoloniaepharmaceutica - drug research, 2001; 58; (6), $415-420$.

Haiyan X, Jing RW, Lee FY, Yong L, Liang L, Quan BH, Zhongzhen Z, Zhi H J. Quantitative Analysis of the Flavonoid Glycosides and Terpene trilactones in the extract of Gingko biloba and evaluation of their inhibitory activity towards fibril formation of $\beta$-Amyloid Peptide. Molecules, 2014; 4: 9, 4466-4478.

José A, Morales G, 2013. The Chemoprevention of Chronic Degenerative Disease Through Dietary Antioxidants: Progress, Promise and Evidences in Oxidative Stress and Chronic Degenerative Diseases - A Role for Antioxidant, Ist ed. Rijeka, Croatia, InTech publisher. pp. 157 162.

Juškait V, Ramanauskien K, Briedis V. Design and Formulation of Optimized Microemulsions for dermal delivery of resveratrol. Evi. Comp. Alt. Med., 2015.

Kürti L, Veszelka S, Bocsik A, Dung NTK, Ózsvári B, Puskás LG, Kittel Á, Szabó-Révész P, Deli MA. The effect of sucrose esters on a culture model of the nasal barrier. Toxicol In vitro, 2012; 26: 445-454.

Kumar S, Pandey AK. Chemistry and Biological Activities of Flavonoids: An Overview. Sci. World J., 2013.

Kamal, MA, Iimura N, Nabekura T, Kitagawa S. Enhanced skin permeation of diclofenac by ion-pair formation and further enhancement by microemulsion. Chem. Pharm. Bull., 2007; 55: 368-371.

Lawrence MJ et al. microemulsion based media as novel drug delivery systems. Adv. Drug Deliv. Rev., 2000; 45, 89 - 121.

Liu X, Peng H, Wang Q, Surface Engineering of Liposomal Formulations for Targeted Drug Delivery. Chem Eng Process Tech, 2014; 2(1): 1024

Loosdrecht V D et al. MTT proliferation assay. J. Imm. Meth., 1994; 174:311-320.

Löf D, Schillén K, Nilsson L., Flavonoids: precipitation kinetics and interaction with surfactant micelles, J Food Sci., 2011; 76(3): N35-39.

McGleenon BM, Dynan KB, Passmore AP. Acetylcholinesterase's inhibitors in Alzheimer's disease. Br J Clin Pharmacol, 
1999; 48(4): 471-480

Murray CJL, Lopez AD, Eds. The global burden of disease: a comprehensive assessment of mortality and disability from diseases, injuries and risk factors in 1990 and projected to 2020. Cambridge, MA, Harvard School of Public Health on behalf of the World Health Organization and the World Bank, 1996 (Global Burden of Disease and Injury Series, Vol. I). (Murray, 1994 and 1996)

Moreau JP, Eck CR, McCabe J, Skinner S. Absorption, distribution and elimination of a labelled extract of Ginkgo biloba leaves in the rat.Presse Med, 1986; 15(31):1458-61.

Meenakshi S, Manicka GD, Tamil mozhi, MS, Arumugam BT. Total Flavanoid and In vitro Antioxidant Activity of Two Seaweeds of Rameshwaram Coast.Glob. J. Pharmacol, 2009; 3 (2): 59-62.

Mandal S, Mandal SS. Microemulsion drug delivery system: A platform for improving dissolution rate of poorly water soluble drug. Int. Jr. of Pharm. Sci. Nanotech, 2011; 3: 4; $1214-1219$.

Mahajan HS, Rasal AD, Microemulsion for nasal drug delivery systems: An overview. Int. Jr. Pharm. Nanotech., 2013, 5(4):1825 - 1831.

Monteagudo E, Gándola Y, González L, Bregni C, Carlucci A. M, Development, Characterization, and In vitro Evaluation of Tamoxifen Microemulsions, Journal of Drug Delivery, 2012.

Moorhead PS. Human tumor cell line with a quasi-diploid karyotype (RPMI 2650), Exp. Cell Res.,1965; 39:190-196

Morales I, Martínez L. G., Cerda-Troncoso C, Farías G. A, Maccioni R. B.,Neuroinflammation in the pathogenesis of Alzheimer's disease. A rational framework for the search of novel therapeutic approaches, Front Cell Neurosci. 2014; 8: 112.

Niles F. World Alzheimer Report 2010: The Global Economic Impact of Dementia, Alzheimer's disease International (ADI), Alzheimer's Association media line, Washington, D.C, 312-335-4078.

Nieoullon A. Neurodegenerative diseases and neuroprotection: current views and prospects, Jr. of Appl Biomed., 2011; 9: 173-183.

Nag P, Rajput R, Dhaliwal S, Kumar S, Prajapat D, Singh M. Formulation and Characterization of Propranolol Nanoparticles for Transmucosal Nasal Drug Delivery, Macromol. Symp., 2015;347: 32-38.

Oken BS, Storzzbach DM, Kaye JA. The efficacy of Ginkgo biloba on cognitive function in Alzheimer disease. Arch Neurol., 1998; 55:1409-15.

Pankevich D. E, Altevogt B.M., I Dunlop J, Gage F. H., Hymanb S. E, Improving and Accelerating Drug Development for Nervous System Disorders. Neuron. 2014; 84(3): 546-553.

Patel R, Patel Y, Kunjadia P, Kunjadia A. DPPH free radical scavenging activity of phenolics and flavonoids in some medicinal plants of India, Int.J.Curr.Microbiol.App.Sci, 2015; 4(1): 773-780.

Patel RB, Patel MR., Bhatt KK, Patel BG. Formulation consideration and characterization of microemulsion drug delivery system for transnasal administration of Carbamazepine. Bull. Fac.Pharm. 2013; 51: 243-253.

Paul BK, Moulik SP. The viscosity behaviours of microemulsions: an overview. PINSA, 2000; 66(5): 499 - 519.

Payghan SA, Kate VK, Purohit S, BhandariA. Goodness of Fit Model Dependent Approach for Release Kinetics And In vitro Release of Piroxicam From Pegs Based Non Aqueous Emulsion, Inventi Rapid: Pharm Tech, 2012; 2012 (3).

Peters GJ, Adema AD, Bijnsdorp IV, Sandvold ML, Lipophilic Prodrugs and Formulations of Conventional (Deoxy)Nucleoside and Fluoropyrimidine Analogs in Cancer. Nucleo. Nucleot. Nucl. Acids, 2011, 30:12, 1168-1180.

Pietta PG, Gardana C, Mauri PL, Identification of Gingko biloba flavonol metabolites after oral administration to humans. J Chromatogr B Biomed Sci Appl. 693:249 - 255.

Privalova AM, Gulyaeva NV, Bukreeva TV. Intranasal administration: a prospective drug delivery route to the brain, Neurochemical J., 2012; 6(2): 77-88.

Pool H, Mendoza S, Xiao H, McClements DJ. Encapsulation and release of hydrophobic bioactive components in nanoemulsion-based delivery systems: impact of physical form on quercetin bioaccessibility. Food Funct, 2013; 4 (1):162-174.
Peter A, Julio DP, Atkins. 2010. Physical Chemistry, 9th ed.: New York, Oxford University Press.

Prieto C, Calvo L. Performance of the Biocompatible Surfactant Tween 80, for the formation of microemulsions suitable for new pharmaceutical processing. J. App. Chem., 2013.

Rao RV, Descamps O, Varghese J, Bredesen D E. Ayurvedic medicinal plants for Alzheimer's disease: a review. Alzheimer's Res Ther., 2012; 4(3): 22.

Rangel OL, Nöldner M, Schubert ZM, Wurglics M. Plasma levels and distribution of flavonoids in rat brain after single and repeated doses of standardized Ginkgo biloba extract EGB 761. Planta Med, 2010; 76(15): 1683-90.

Ramteke KH, Dighe PA, Kharat AR., Patil SV, Mathematical Models of Drug Dissolution: A Review, Sch. Acad. J. Pharm., 2014; 3(5): 388-396

Sis H, Brinci M. Adsorption characteristics of ionic and non ionic surfactant on hydrophobic pigment in aqueous medium. Col. tech., 2012; 128(3): $244-249$.

SarkhejiyaNA,Nakummayur A, Patel V, Atara SA, Desai T. Emerging trend of microemulsion in formulation and research. Int. Bull. Drug Res., 2005;1(1): 54-83.

Syed HK, Peh KK. Identification of phases of various oil, surfactant/ co-surfactants and water system by ternary phase diagram. Acta Pol Pharm., 2014; 71(2):301-9.

Shafiq S, Shakeel F, Enhanced stability of ramipril in Nanoemulsion containing Cremophor-EL: a technical note. AAPS Pharm Sci Tech., 2008; 9:1097-1101.

Sahoo SK, Dilnawaz F, Krishankumar S. Nanotechnology in ocular drug delivery. Drug discov. today. 2007, 13:3 (4), pp 144 - 151.

Sahoo NG, Kakran M, Shaal LA, Li L, Muller RH, Pal M, Tan LP. Preparation and Characterization of Quercetin Nanocrystals. J Pharm Sci-Us., 2011;100 (6):2379-2390.

Sarkhejiya NA, Nakum MA, Patel VP, Atara SA, Desai T. Emerging trend of microemulsion in formulation and research. Int Bull.Drug Res., 2011;1(1): 54-83.

Schmidt MC, PeterH, Lang SR, Ditzinger G, Merkle HP. In vitro cell models to study nasal mucosal permeability and metabolism. Adv. Drug Del. Rev., 29(2):51-79, 1998.

Sperling RA, Parak WJ, Surface modification, functionalization and bio conjugation of colloidal inorganic nanoparticles. Phil. Trans. R. Soc. 2010, 368, 1333-1383.

Thilakarathna S. H, Rupasinghe H.P.V. Flavonoid Bioavailability and Attempts for Bioavailability Enhancement. 2013, 5(9): 3367-3387.

Vandamme TF, Microemulsions as ocular drug delivery systems: recent development and future challenges. Prog. Retin. Eye Res. $2002,21,15-34$.

Wei T, Ni Y, Hou J, Chen C, Zhao B, Xin W. Hydrogen peroxide-induced oxidative damage and apoptosis in cerebellar granule cells: Protection by Ginkgo biloba extract. Pharmacol. Res., 2000; 41:427433.

Wadell C, Bjork E, Camber O. Permeability of porcine nasal mucosa correlated with human nasal absorption. Eur. Jr. Pharm. Sci., $2003 ; 18(1): 47-53$.

Wolinsky JB, Mark W, Grinstaff. Therapeutic and diagnostic applications of dendrimers for cancer treatment, Adv. Drug Deliv. Rev. 2008, 60, 1037-1055.

World Health Organization 1999, "WHO monographs on selected medicinal plants-Vol. 1", WHO Library Cataloguing in Publication Data, NLM Classification: QV 766, ISBN 9241545178.

Woelkart K, Feizlmayr E, Dittrich P, et al. Pharmacokinetics of bilobalide, ginkgolide $\mathrm{A}$ and $\mathrm{B}$ after administration of three different Ginkgo biloba L. preparations in humans. Phytother. Res. 2010; 24:445450 .

Xie J, Ding C, Ge Q, et al. Simultaneous determination of ginkgolides A, B, C and bilobalide in plasma by LC-MS/MS and its application to the pharmacokinetic study of Ginkgo biloba extract in rats. J Chromatogr B. 2008; 864:87-94. 
Xiuzhen H, Tao S, HongxiangL. Dietary Polyphenols and Their Biological Significance. Int. J Mol Sci., 2007; 8(9): 950-988.

Washington N, Steele RJ, Jackson SJ, Bush D, Mason J, Gill DA, Pitt K, Rawlins DA. Determination of baseline human nasal $\mathrm{pH}$ and the effect of intranasally administered buffers. Int. J Pharm., 2000; 5;198(2):139-46.

Ying W, Ke CW, Bing XZ, Xin ZX, Wang SC, Shu FN, Wei SP, Xuan Z, Qiang Z. A Novel Paclitaxel Microemulsion Containing a Reduced Amount of Cremophor EL: Pharmacokinetics, Biodistribution, and In Vivo Antitumor Efficacy and Safety. J. Biom. Biotech., 2011;2011.

Zhang J, Michniak KB. Investigation of microemulsion microstructures and their relationship to transdermal permeation of model drugs: ketoprofen, lidocaine, and caffeine. Int J Pharm., 2011;112; 421(1):34-44.

\section{How to cite this article:}

Singh M, Singh SP, Rachana R. Development, characterization and cytotoxicity evaluation of Gingko biloba extract (EGB761) microemulsion for intranasal application. J App Pharm Sci, 2017; 7 (01): 024-034. 